\title{
Design of Remote Corrosion Detection System in the Marine Structure Using an Anisotropic Magnetic Resistance Sensor
}

\author{
S. Jegadeesan \\ Department of Electronics and Communication Engineering, M.Kumarasamy College of Engineering, Karur-639113, Tamilnadu.
}

Received 26 March 2019; Accepted 14 November 2021

\begin{abstract}
Corrosion in the ship can create severe damage to structures, such as a leak, crack and it leads to many maritime disasters (oil tankers) and it creates a lot of pollution, a problem for the environment and the inhabitants of the affected coasts. Hence, the detection and prevention of corrosion in a ship are very important to ensure safety. Many conventional methods like eddy current testing (ECT) are available as a non-destructive testing (NDT) scheme for analyzing defects in the metal sheets. However, these conventional methods are not suitable for analyzing objects build by using ferromagnetic materials due to permeability fluctuation. Hence, an efficient method is proposed to identify the corrosion in the ship structure by measuring the thickness of metal sheets periodically. The proposed system measures the thickness of metal sheet in the ship structure with the help of anisotropic magnetic resistance sensors. Also, the proposed system detects the corrosion in critical areas of ships without taking them out of the water. To avoid the influence of the liftoff, the proposed system measures the thickness of an object by using the phase spectrum instead of a magnetic spectrum curve. Furthermore, the proposed system effectively analyzes the corrosion of a metal sheet with less time and accuracy when the corrosion is more than $10 \%$.
\end{abstract}

Keywords: Non-destructive testing, Permeability fluctuation, Corrosion detection, Thickness measurement, Anisotropic magnetic resistance sensor.

\section{Introduction}

For developing countries like India, increasing facilities and infrastructure such as bridges, buildings, nuclear power plants, concrete structures, pipelines, storage tanks, aircraft, ships, cars, trucks, and machinery is very important. Many of these infrastructures are developed by steel plates. But the steel plates are affected by corrosion due to interaction with its environment and corrosion can create serious damage to structures, which include leak, crack and finally, it leads to the breakdown of the structure itself and it is very important to ensure the quality, life, and safety of an infrastructure developed by the steel plate [1]. In this paper, we have considered one of the main steel infrastructures as ships. In ship transportation, many maritime disasters with crude oil tankers occurred. It creates a lot of pollution, a problem for the environment and the inhabitants of the affected coasts. These accidents occur due to human error and material degradations of the ship. Corrosion plays an important role in the degradation of materials in the ship. Therefore, it is necessary to develop an effective and efficient corrosion detection and prevention method [2].

Many inspection methods are available for analyzing the steel corrosion [3], the popular inspection methods are ultrasonic testing, electrochemical scheme, radiographic testing, infrared thermography, X-ray diffraction, and ECT [4-5], which is shown in Fig. 1. Many metallic structures are made up of ferromagnetic material. The imperfection in the ferromagnetic materials may alter the magnetic properties and

*E-mail address: jegadeesans@rediffmail.com ISSN: 1791-2377 (C) 2021 School of Science, IHU. All rights reserved. doi:10.25103/jestr.145.05 structure of an object. These changes are used to analyze the structure of the steel plate, such as corrosion detection, stress concentration, etc. This technique is called NDT. Many NDT schemes are available, like magneto acoustic emission, magnetic barkhausen emission, and magnetic field leakage. These schemes are also known as active magnetic test schemes, but they require more time to analyze the structure of the steel plate and difficult to analyze the uneven structure [6-8].

ECT is the best method to analyze the ferromagnetic material structure. Since the ECT scheme utilizes a proper tool to analyze the structure of the steel plate. Moreover, it can easily detect the defects in the metallic structure which is in the low skin depth. But it increases the magnetic noise during the analysis [9]. The frequency has to be reduced to identify the corrosion in the thick skin metal sheet by using the ECT scheme. To analyze the metal object, the magnetic and eddy current dispersion has to be described in developing a magnetic spectrum [10-12]. But, only less number of substances such as backside crack in $10 \mathrm{~mm}$ thickness plate [13-14] and $0.5 \mathrm{~mm}$ thickness change in the stainless steel material can be analyzed, and also it is difficult to remove the magnetic fluctuation from the magnetic field derived from the metal object [15-16].

Therefore, the main objective of this paper is to develop a new NDT method to analyze the corrosion present in the 20 $\mathrm{mm}$ thick metal sheet used in the ship structure, especially in the oil tanker to avoid pollution and problems in the sea environment. The proposed scheme remotely identifies and measures the effect of corrosion present in the ship structure more accurately by using the magnetic spectrum and phase spectrum. 


\section{Related works}

The marine structures are affected by atmospheric corrosion due to the interaction with the seawater.

The following environmental factors affect the marine structures and it leads to corrosion. The environmental factors are Seawater temperature, Dissolved oxygen, Water salinity,
Seawater velocity, Seawater $\mathrm{pH}$, Marine growth and bacteria, Depth of immersion, Season of initial immersion, Possible contacts with other materials, Organic material in seawater, and Other environmental factors [17-18]. Many ship accidents were occurring due to human error and material degradation or corrosion in recent years.

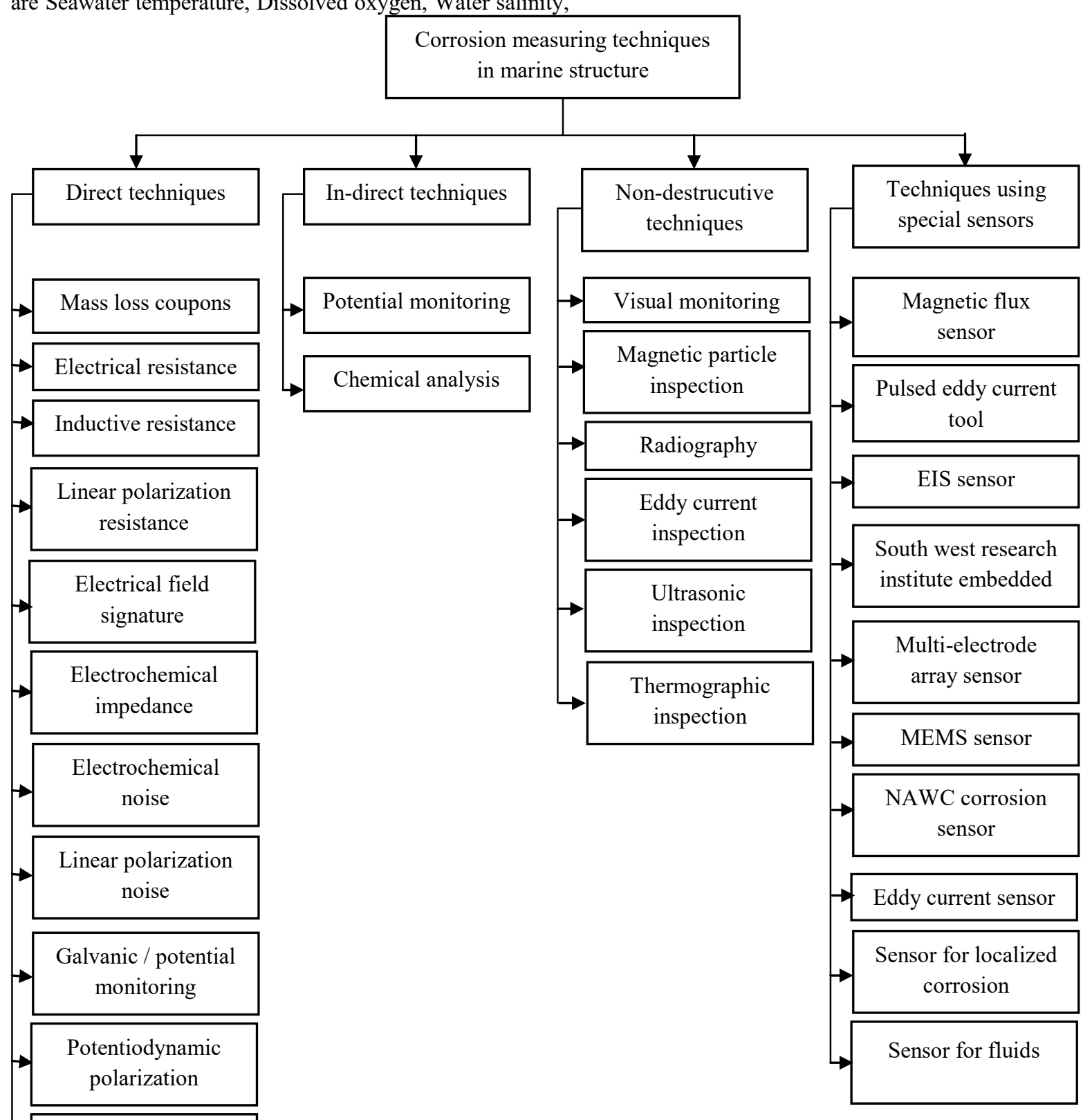

Acoustic emission

Fig. 1. Corrosion measurement techniques.

In modern civilization, oil plays a major role in energy production. The oils are transported from source to processing places and customers over distances. Mainly the oils are transported through oil tankers in the sea. The material degradation and corrosion in the ship structure may lead to an enormous amount of oil leakage into the sea and it spoils the marine environment. Majorly it affects sea animals. In European countries, oil and oil products are transported maximally through the sea. Most of the accidents were occurring in oil tankers and it creates pollution in the sea environment. Examples of oil tanker accidents are, Torrey canyon accident: 31 million gallons of oil leaked into the sea and it spreads from England to France. A lot of sea animals are killed and affected due to this accident. Amoco cadiz: 68.7 million gallons of oil leaked into the sea. Exxon valdez: around 11 million gallons of oil leaked into the sea. Braer: 85000 tonnes of oil leaked into the sea and it creates a huge amount of pollution to the sea environment in Scotland. Erika accident: 20000 tonnes of oil leaked into the sea and it spoiled the French coast around $400 \mathrm{~km} \mathrm{[19].} \mathrm{As} \mathrm{mentioned} \mathrm{earlier,}$ most of the accidents are occurred due to human error and material degradation, and undetected corrosion. Material degradation and corrosion in the material were identified by performing ship surveys periodically based on the age and 
type of structure. Carvalho et al. discussed and analyzed different corrosion marvels that affect the steel structure. Also, they presented the various corrosion models and their capability to calculate the corrosion present in the hull. Melchers $\mathrm{R}$ introduced two new methods to identify the corrosion. The first method identifies the corrosion based on the supervised classification method and texture roughness criteria. The second method identifies corrosion using the classifiers approach and color analysis [20]. The electrochemical sensor was designed to identify the corroded area in the metal sheet. Many researchers have investigated the corrosion and crack growth rates. The stress corrosion cracking controlling methods is developed to support the owners to maintain the stress corrosion cracking. Several assessments, monitoring methods, and life cycle controlling with respect to ship corrosion monitoring and to develop the system to monitor the health of ship structures. Also, they have discussed several criteria for assessing the health condition of the metal sheet [21]. The above-discussed schemes provide the solution for measuring the thickness of corrosion in the ship structure. But, they are affected by consuming more time, and also the measurements are taken randomly. In the proposed work, the depth of corrosion in the steel structure is measured remotely in a more accurate manner by improving the sensing section and analysis scheme for the magnetic spectrum. Also, the steel plate thickness measurement values are communicated to the controller to take the necessary steps to avoid further damages to the ship structure.

\section{Proposed Method}

3.1. A magnetic field evaluation scheme to detect the corrosion in the ship structure by measuring the metal sheet thickness

The proposed method uses an anisotropic magnetic resistance sensor to identify the corrosion present in the ship structure by measuring the metal sheet thickness. The corrosion measurement techniques in the marine structures are shown in Fig. 2. It consists of a steel plate thickness measurement system, local server, cloud, and monitor/controller. All the pieces of equipment are connected through the internet. A steel plate thickness measurement system with a magnetic resonance sensor is fixed in the ship structure to identify the corroded area in the ship to prevent accidents. The measured values from the sensor transferred to the monitor/controller with the help of the cloud and local servers. If the measured value is greater or lesser than the actual thickness of the metal sheet, then the controller will alert the ship captain or the ship owner to take necessary action to avoid damages to the ship structure.

For the experimental study, we have developed a steel plate thickness measurement system, which consists of an anisotropic magnetic resistance sensor, induction coil, an elimination coil, function generator, and digital lock-in amplifier, which is shown in Fig. 3. Technical specifications of devices used in this study are listed in Tab. 1. The sensor in the proposed method is used to detect the magnetic field reflected from the object; the electromagnetic field is applied to a metal sheet by using an induction coil. An elimination coil is fixed around the sensor to increase the signal to noise ratio of a signal obtained from the sensor and the function generator is used to control the current source applied to the induction coil. The digital lock-in amplifier is used to extract the output signal from a noisy environment.

The inductance coil is connected in series with an elimination coil in a similar phase. The induction coil wound circularly about $30 \mathrm{~mm}$ in width and it has 60 rounds. The coil is supplied by 0.1 Ampere AC current from the frequency 1 $\mathrm{Hz}$ to $1 \mathrm{kHz}$. In the proposed work, many magnetic resistance sensors are fixed to identify the corrosion in the ship structure. The degradation of material can be identified by energizing the proposed sensors frequently. It will determine the presence and growth of corrosion by measuring the thickness of the metal sheet in the ship structure.

\subsection{Analysis of magnetic field reflected from the metal sheet}

The inductance coil applies the magnetic field to a measuring object and the reflected magnetic signal from an object is measured by using a sensor and it is analyzed with the help of a digital lock-in amplifier. In the traditional schemes, the magnetic spectrum and phase spectrum are analyzed by using impedance variations in the detected signal. In the proposed method, the sensor directly detects the magnetic signal reflected from the metal sheet with uniform sensitivity because the system does not depend on frequency. The detected magnetic signal contains a magnetic field developed by eddy current as well as the residual magnetic field. The total magnetic field applied to an object is calculated by removing the residual magnetic field from the detected magnetic signal [22].

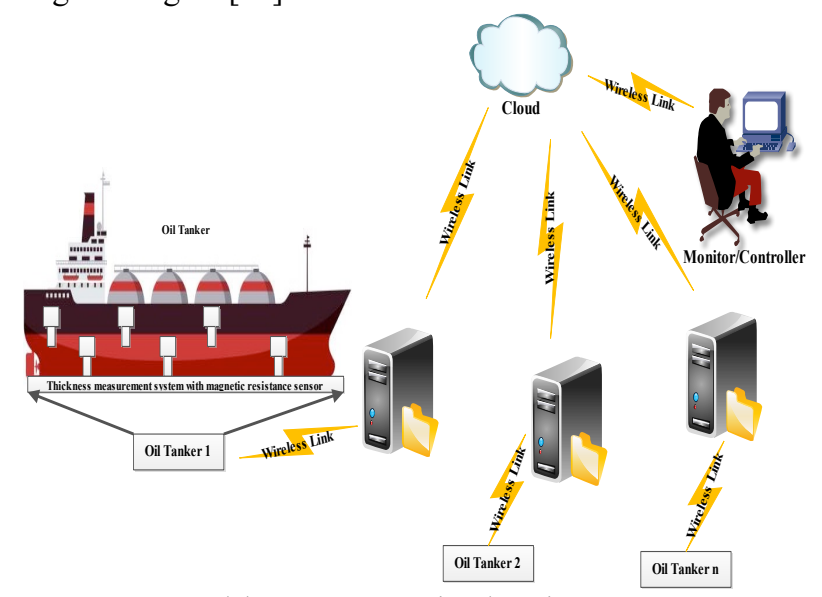

Fig. 2. System model - Remote corrosion detection

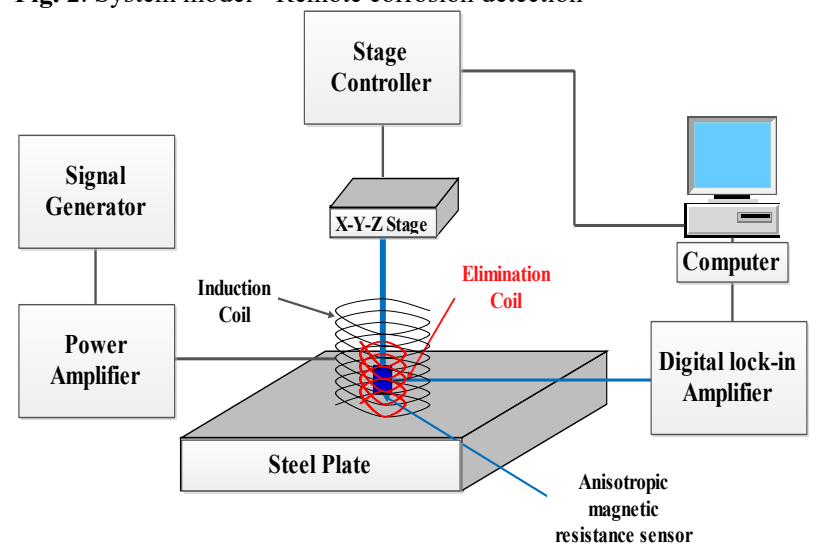

Fig.3. Experimental setup - Steel plate thickness measurement system 
Table 1. Technical specification of devices used in this study.

\begin{tabular}{|c|c|c|c|}
\hline S.No. & Name of the device & Specification & $\begin{array}{r}\text { Purpose } \\
\end{array}$ \\
\hline 1 & Inductance coil & $30 \mathrm{~mm}$ width and 60 turns & $\begin{array}{l}\text { To apply the magnetic field to the } \\
\text { metal sheet }\end{array}$ \\
\hline 2 & Elimination coil & $3 \mathrm{~mm}$ width and 15 turns & To improve the SNR \\
\hline 3 & $\begin{array}{l}\text { Anisotropic magnetic } \\
\text { resistance sensor }\end{array}$ & $\begin{array}{c}\text { MMC3416xPJ } \\
\text { Sensitivity: } 2048 \mathrm{c} / \mathrm{G} \\
\text { Size: } 1.6 \mathrm{~mm} \times 1.6 \mathrm{~mm} \\
\text { LI5640 }\end{array}$ & $\begin{array}{l}\text { To detect the reflected signal from the } \\
\text { metal sheet }\end{array}$ \\
\hline 4 & Digital lock-in amplifier & $\begin{array}{c}\text { Phase stability: } 0.01{ }^{\circ} /{ }^{\circ} \mathrm{C} \\
\text { Gain stability: } \pm 100 \mathrm{ppm} /{ }^{\circ} \mathrm{C} \text {. }\end{array}$ & To analyze the detected signals \\
\hline
\end{tabular}

$$
M_{\mathrm{t}}=M_{\mathrm{d}}-M_{\mathrm{r}}
$$

Where,

$$
\begin{aligned}
& M_{\mathrm{d}} \text { - Detected magnetic signal } \\
& M_{\mathrm{r}} \text { - Residual magnetic field } \\
& M_{\mathrm{t}} \text { - Total magnetic field }
\end{aligned}
$$

The magnetic field measured from the object consists of the eddy current magnetic field component as well as the magnetization characteristics of a measuring object.

$$
M_{\mathrm{d}}=M_{\mathrm{ec}}+M_{\mathrm{mg}}
$$

where,

$$
M_{\mathrm{ec}} \text { - Eddy current magnetic field }
$$

$M_{\mathrm{mg}}$ - Magnetization of a measuring object

The eddy current magnetic field in an object can be written as:

$$
M_{\mathrm{ec}}=-k_{1} I_{\mathrm{c}} \frac{\omega^{2} L}{R^{2}+\omega^{2} L^{2}} e^{i \omega t}-k_{2} I_{c} \frac{\omega R}{R^{2}+\omega^{2} L^{2}} e^{i \omega t}
$$

Therefore, the detected magnetic field from an object can be written as:

$$
M_{\mathrm{d}}=\left(-k_{1} I_{c} \frac{\omega^{2} L}{R^{2}+\omega^{2} L^{2}} e^{i \omega t}-k_{2} I_{c} \frac{\omega R}{R^{2}+\omega^{2} L^{2}} e^{i \omega t}\right)+M_{\mathrm{m}}
$$

where,

$$
I_{\mathrm{c}} \text { - Inductance current applied to the coil, which is directly }
$$
proportional to the magnetic field generated by the coil $\omega$ - Angular frequency

\section{$k$ - Constant}

$R$ - Resistance of a measuring object

$L$ - Inductance of a measuring object

To detect the corrosion area in the ship structure, the experiment was conducted with a specimen of $12 \mathrm{~m} \times 8 \mathrm{~m}$ size and a $20 \mathrm{~mm}$ thick metal sheet to represent the steel plate used on tanker floors. For the measurement, the corrosion in the metal sheet was introduced artificially and the corroded area of a steel plate was identified by measuring the thickness of a specimen metal sheet. Also, the proposed method can detect the depth of corrosion from $20 \%$ to $80 \%$.

\section{Results and Discussion}

\subsection{Measuring the thickness of a metal sheet}

In the proposed work, to monitor the condition of the ship structure remotely, the magnetic field is applied to the ship structure periodically or on-demand basis. Then, the magnetic signals are collected from the metal object at a low frequency of $1 \mathrm{~Hz}$, which is equal to $M_{m g}$ and the initial magnetic permeability of the metal sheet. Normally, an object has an initial permeability and a residual magnetic field $M_{r}$. Measuring the thickness of an object is difficult in the conventional ECT method due to the permeability fluctuation. To reduce the permeability fluctuation, the magnetic spectrum curve begins at zero on the $x$-axis by removing the $\mathrm{M}_{\mathrm{mg}}$. Therefore, the magnetic spectrum curve contains only the eddy current magnetic field $\mathrm{M}_{\mathrm{ec}}$.

$$
M_{\mathrm{ec}}=M_{\mathrm{d}}-M_{\mathrm{mg}}
$$

After removing the $\mathrm{M}_{\mathrm{mg}}$ from the detected magnetic field, the thickness measurement of a metal sheet is very easy at the lower frequency range. Therefore, the electromagnetic waves can measure the thickness of thick skin metal sheets. In this experiment, the proposed method measures the thickness of a $20 \mathrm{~mm}$ thick skin metal sheet by using electromagnetic waves.

\subsection{Measuring the thickness of a metal sheet by phase spectrum}

The applied magnetic field on a metal sheet mainly depends on the distance from magnetic sources to the measuring object. After removing the $\mathrm{M}_{\mathrm{mg}}$ from the magnetic spectrum, the detected magnetic field intensity of an object is still disturbed by the effect of liftoff.

To reduce the liftoff effect, the value of liftoff is changed from $4 \mathrm{~mm}$ to $6 \mathrm{~mm}$. There is a gradual decrement in the intensity of the magnetic field curve based on the changes in the liftoff value. The magnetic field intensity identifies the corrosion when the corrosion depth of more than $60 \%$, which is shown in Fig. 4. But, there is no major change in the phase of the magnetic field and the phase spectrum identifies the corrosion shape even at $20 \%$ corrosion depth, shown in Fig. 5. By comparing Figs. 4 and 5, it is very clear that the proposed method can identify the corrosion in earlier stages. The thicknesses of a metal sheet are measured accurately by using a phase spectrum compared with magnetic field intensity.

Normally, to find the magnetic spectrum, the applied field frequency should be changed from low frequency to high frequency. But, to improve the speed of measurement the magnetic spectrum frequency range should be reduced. 
Therefore, in the proposed method, the magnetic spectrum of the magnetic field spectrum curve. a metal sheet is obtained in the low-frequency range. Fig. 6 shows the thickness measurement of a metal sheet by using

(a)

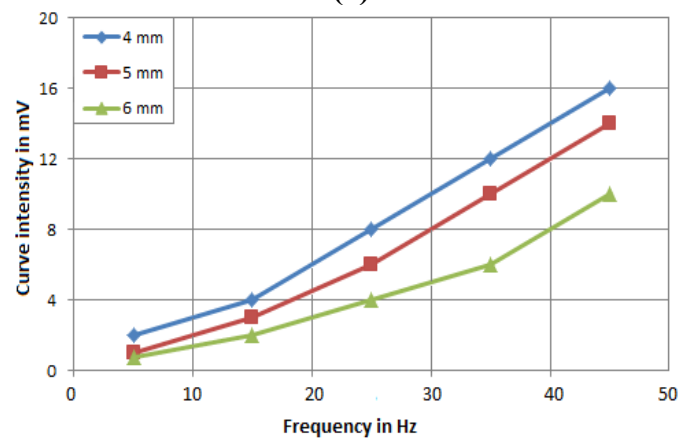

(b)
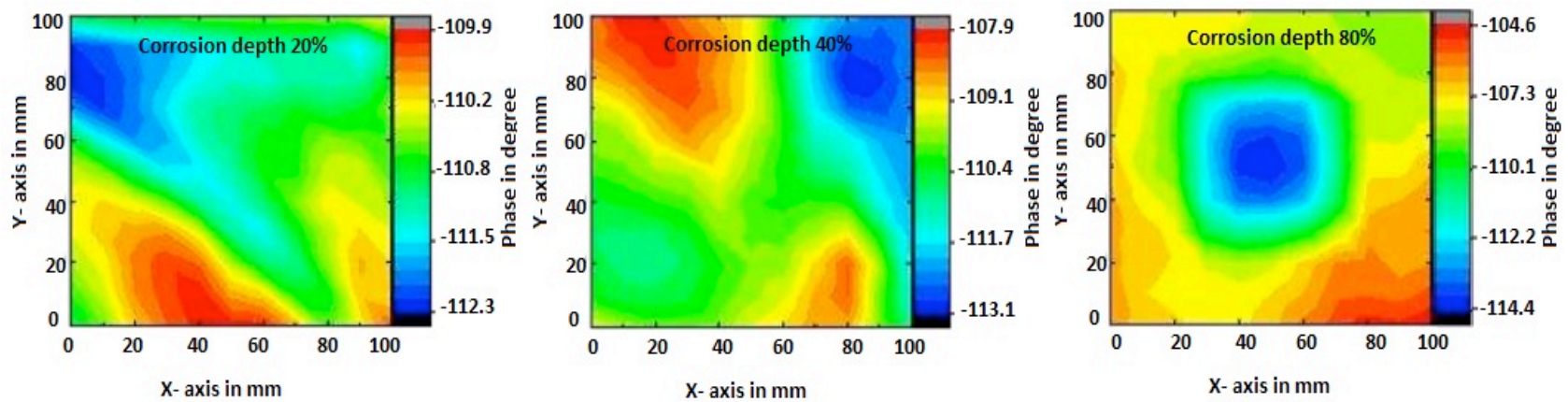

Fig.4. (a) Effect of different liftoff in the magnetic field intensity (b) Magnetic field intensity for different corrosion depth.

(a)

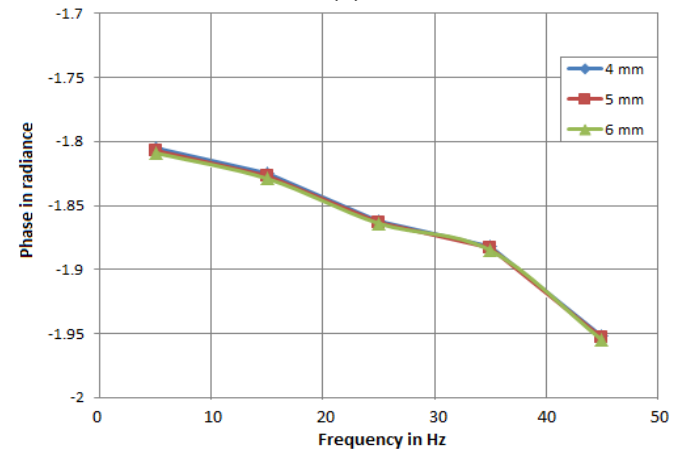

(b)
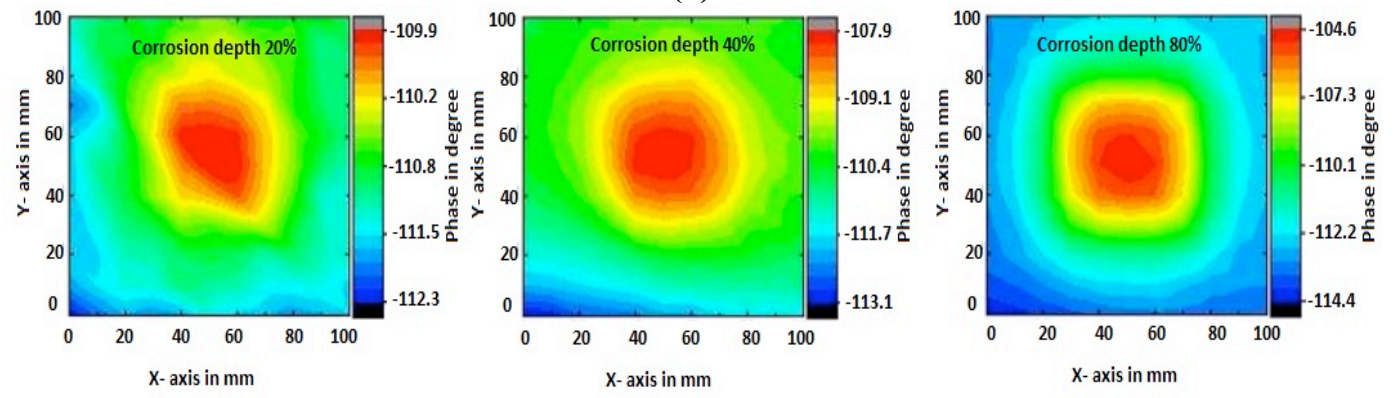

(b)

Fig.5. (a) Effect of different liftoff in the phase spectrum (b) Phase spectrum for different corrosion depth.

\subsection{Metal sheet thickness measuring time and accuracy} To find the magnetic spectrum of a metal sheet, the frequency has to be varied from low to high. In the proposed method, high-frequency signals are not required for measuring the thickness of an object. Therefore, the proposed method improves the measuring time. The thickness of an object is 
measured based on the characteristics of the magnetic spectrum derived from the metal sheet. Magnetic spectrum characteristics are mainly related to the differential magnetic vector [14].

$M_{e c, d m v}=M_{e c, f_{2}}-M_{e c, f_{1}}$

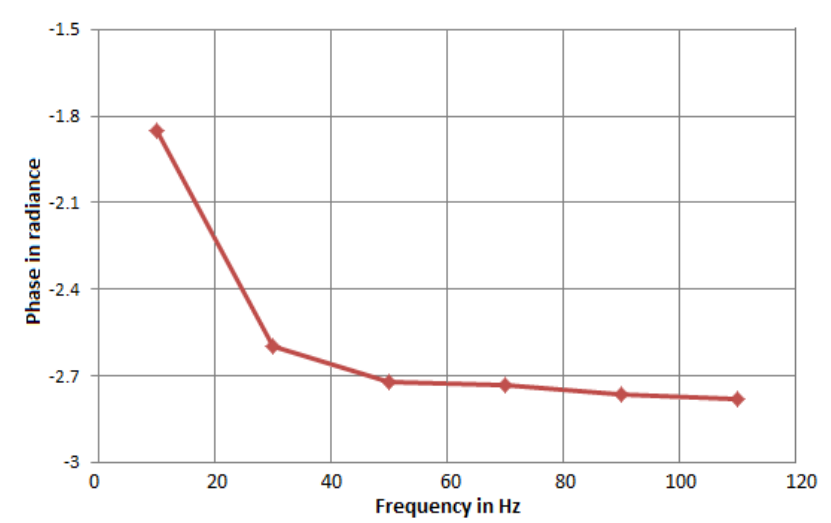

Fig.6. Phase spectrum of $20 \mathrm{~mm}$ thick metal sheet.

The magnetic spectrum curve requires a beginning point $\mathrm{M}_{\mathrm{mg}}$ in the $x$-axis, find at the low frequency of $1 \mathrm{~Hz}$ to move to the starting point of the coordinates. But, the differential magnetic vector does not require $\mathrm{M}_{\mathrm{mg}}$ measurement. Since it retains the same vector irrespective of changes in the origin of the magnetic spectrum curve. Therefore, a long time is not required to measure the value of $\mathrm{M}_{\mathrm{mg}}$ in the differential vector method. Hence, the metal sheet thickness measurement process consumes less time. Also, the proposed system measures the thickness of an object by using the phase spectrum instead of a magnetic spectrum curve. Therefore, it avoids the influence of the liftoff.

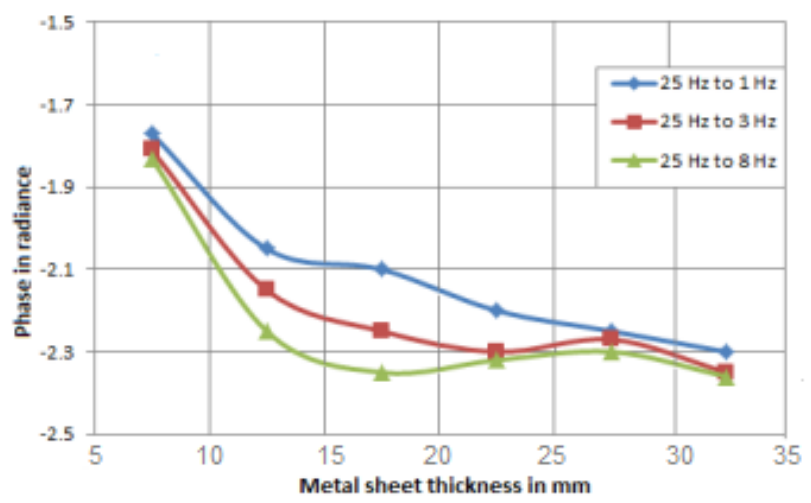

Fig.7. Thickness measurement for different phase value.

\subsection{Detection of corrosion depth in the metal sheet}

The depth of corrosion is measured for a $20 \mathrm{~mm}$ thick specimen metal sheet. For the experiment, the frequency range is selected at $25 \mathrm{~Hz}$ is considered as $f_{2}$ and $10 \mathrm{~Hz}$ is considered as $f_{1}$ shown in Fig. 7. The penetration of the magnetic field in the phase spectrum of the differential magnetic vector is shown in Fig. 8. The phase spectrum effectively analyzes the corrosion of a metal sheet when it is more than $10 \%$. Therefore, the phase spectrum analysis of the differential magnetic vector efficiently detects the corrosion of the metal sheet.

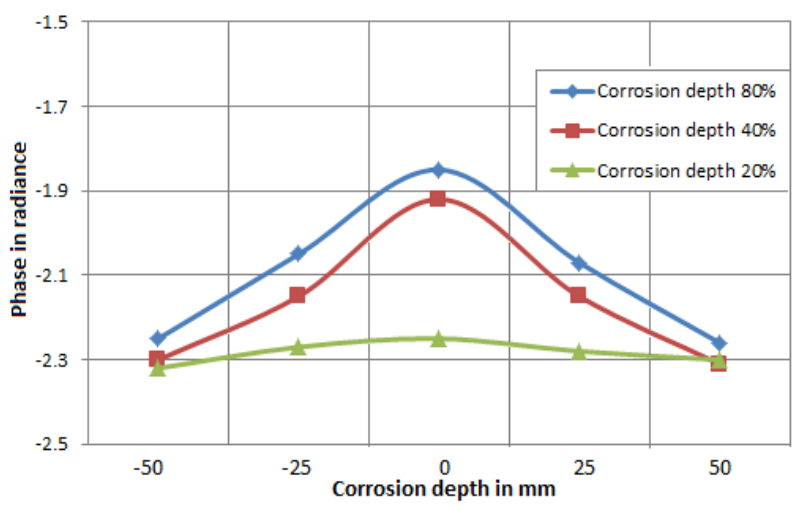

Fig.8. Corrosion area and depth of corrosion.

Tab. 2 explains the performance of the proposed work when compared to other existing works. The visual inspection method can detect the crack and corrosion point only on the accessible surface, not on the non-accessible surface [22]. The ultrasonic method identifies the crack location in both accessible and non-accessible surfaces. But it can identify the corrosion presence only in the non-accessible surface [23].

The magnetic particle identification method has the capability of detecting the crack location of inaccessible surfaces [24]. The liquid penetrant method also has the ability to detect the location of crack present in the accessible surfaces [25]. The acoustic emission method can identify the crack present in the accessible surface as well as nonaccessible surfaces. But this method unable to detect the corrosion present in the marine structure [26]. The location of cracks and corrosion present in the non-accessible surfaces are identified by using a leak detection method [27]. Crack locations of the accessible and non-accessible surfaces, as well as corrosion locations in the non-accessible surfaces, are identified using the field signature and eddy current method [28-30]. But, our proposed method can easily detect the location of cracks and corrosion in both accessible and nonaccessible surfaces with accuracy.

Table 2. Comparison of the proposed method with existing methods

\begin{tabular}{|c|c|c|c|c|c|}
\hline \multirow[t]{2}{*}{ S.No. } & \multirow[t]{2}{*}{ Method } & \multicolumn{2}{|c|}{ Crack detection ability } & \multicolumn{2}{|c|}{ Corrosion detection ability } \\
\hline & & $\begin{array}{c}\text { Accessible } \\
\text { surfaces }\end{array}$ & $\begin{array}{c}\text { Non-accessible } \\
\text { surfaces }\end{array}$ & $\begin{array}{l}\text { Accessible } \\
\text { surfaces }\end{array}$ & $\begin{array}{c}\text { Non-accessible } \\
\text { surfaces }\end{array}$ \\
\hline 1 & $\begin{array}{l}\text { Visual inspection (Yang's } \\
\text { et al) }\end{array}$ & $\checkmark$ & - & $\checkmark$ & - \\
\hline 2 & $\begin{array}{l}\text { Ultrasonic (Sano's } \\
\text { et al) }\end{array}$ & $\checkmark$ & $\checkmark$ & - & $\checkmark$ \\
\hline 3 & $\begin{array}{l}\text { Magnetic particle } \\
\text { (Kovalenko's et al) }\end{array}$ & $\checkmark$ & - & - & - \\
\hline 4 & $\begin{array}{l}\text { Liquid penetrant (Bedi's et } \\
\text { al) }\end{array}$ & $\checkmark$ & - & - & - \\
\hline 5 & Acoustic emission & $\checkmark$ & $\checkmark$ & - & - \\
\hline
\end{tabular}




\begin{tabular}{|c|c|c|c|c|c|}
\hline 6 & $\begin{array}{l}\text { (Emilianowicz's et al) } \\
\text { Leak detection (Wang's et }\end{array}$ & - & $\checkmark$ & - & $\checkmark$ \\
\hline 7 & $\begin{array}{r}\text { Field signature (Gan's et } \\
\text { al) }\end{array}$ & $\checkmark$ & $\checkmark$ & - & $\checkmark$ \\
\hline 8 & $\begin{array}{l}\text { Eddy current (Harzallah's } \\
\text { et al) }\end{array}$ & $\checkmark$ & $\checkmark$ & - & $\checkmark$ \\
\hline 9 & Proposed method & $\checkmark$ & $\checkmark$ & $\checkmark$ & $\checkmark$ \\
\hline
\end{tabular}

\section{Conclusion}

In this paper, we proposed an efficient system to detect the corrosion and cracks present in the ship structure at earlier stages to avoid damages or accidents. The proposed system detects the corrosion and cracks remotely by measuring the thickness of the steel plate periodically or on-demand basis. The system uses the anisotropic magnetic resistance sensors to senses the reflected magnetic field of an object and analyzes the magnetic spectrum, phase spectrum curve to detect the corrosion present the metal sheet. Also, the system can analyze the depth of corrosion in a quick time with greater accuracy. To avoid the liftoff effect, the thickness of a metal sheet is measured by the phase spectrum instead of the magnetic spectrum.

This is an Open Access article distributed under the terms of the Creative Commons Attribution License.

\section{References}

1. Arturo Gonzalez, Michael Schorr, Benjamin Valdez and Alejandro Mungaray, IntechOpen, (2020).

2. Handbook on Infrastructure Statistics, Africa Infrastructure Knowledge Program, African Development Bank Group, (2011).

3. Thangavel, K., Innovations in Corrosion and Materials Science, 7, 2, (2018).

4. Kim H, Kang D, and Jung S W, Chinese Journal of Oceanology and Limnology, 37, 4, (2019).

5. Brodnan M, Koteš $\mathrm{P}$, and Vanerek J, Materiali in Tehnologije, 51, 1, (2016).

6. Milella A, Maglietta R, and Caccia M, Sensor Review, 37, 4, (2017).

7. Mohammed Berka, Zoubir Mahdjoub, and Mourad Hebali, Journal of Electrical Engineering, 69, 4, (2018).

8. S Jegadeesan, M Dhamodaran, M Azees, S Sri Shanmugapriya, Journal of Magnetics, 23, 2, (2018).

9. Zheng X, Xia D, and Wang H, Anti-Corrosion Methods and Materials, 60, 3, (2013).

10. M Dhamodaran, R Praveen Kumar, S Jegadeesan, Journal of Magnetics, 23, 1, (2018).

11. Jakubowski M, Polish Maritime Research, 21, 1, (2013).

12. Babu P, Mathiazhagan A, and Nandakumar C, International Journal of Environmental Science and Development, 5, 5, (2014).

13. Zadow L, Gamboa E, and Lavigne O, Materials and Corrosion, 66, 10, (2014).

14. M Dhamodaran, S Jegadeesan, A Murugan, Journal of Electrical Engineering, 70, 5, (2019).

15. Muscat R, and Wilson A, IEEE Sensors Journal, 17, 24, (2017).
16. M Dhamodaran, $\mathrm{S}$ Jegadeesan, $\mathrm{R}$ Praveen Kumar, Cluster Computing, 22, 6, (2019).

17. Kim K, Kwon J, and Kang N, IEICE Electronics Express, 13, 17, (2016).

18. Guedes Soares C, Garbatov Y, and Zayed A, Corrosion Engineering Science and Technology, 46, 4, (2011).

19. Du G, Wang W, Song S, and Jin S, Anti-Corrosion Methods and Materials, 57, 3, (2010).

20. Carvalho A, Sagrilo L, Silva I, Rebello J and Carneval R, Applied Ocean Research, 25, 5, (2003).

21. Melchers R, Structure and Infrastructure Engineering, 2, 1, (2006).

22. A. Ziouche, M. Zergoug, N. Boucherrou, H. Boudjellal, M. Mokhtari, and S. Abaidia, Russian J. Nondestruct., 53, 9, (2017).

23. Yang, Y. and Cheng, F, Corrosion, 4, 1, (2016).

24. Sano $\mathrm{K}$ and Matsuo $\mathrm{T}$, The Abstracts of ATEM : International Conference on Advanced Technology in Experimental Mechanics : Asian Conference on Experimental Mechanics, 14, 1, (2015).

25. Kovalenko A, Kontrol'. Diagnostika (2014).

26. Bedi R and Mehta B, International Journal of Experimental Design and Process Optimisation, 5, 1, (2016).

27. Emilianowicz K, Polish Maritime Research, 21, 1, (2013).

28. Wang F, Shui A, and Zeng L, International Journal of Heat and Technology, 36, 3, (2018).

29. Gan F, Wan Z, Liao J, and Li W, Insight - Non-Destructive Testing and Condition Monitoring, 56, 11, (2014).

30. Harzallah S, Chabaat $\mathrm{M}$, and Chabane $\mathrm{K}$, Frattura ed Integrità Strutturale, 11, 39, (2016). 